\title{
The study and conservation of adders in Scotland
}

\author{
C.J. McInerny
}

University of Glasgow, President Glasgow Natural History Society (GNHS), Chairman Biological Recording in Scotland (BRISC), and Clyde Amphibian and Reptile Group (CARG)

School of Life Sciences, University of Glasgow, Glasgow G12 8QQ

E-mail: Chris.McInerny@glasgow.ac.uk

\begin{abstract}
This paper describes two projects that explored the study and conservation of European adders (Vipera berus) and other reptiles in Scotland. One involved the implementation of an environmental mitigation plan during the construction of a hydroelectric scheme through an area of high reptile densities. The other involved the monitoring of a population of adders in a highly managed environment on a golf course. In both cases the adder numbers persisted suggesting that the populations were not affected, and so they illustrate situations where this reptile species can co-exist with humans. Finally, more general observations about reptile habitat requirements and conservation in Scotland are inferred from these studies.
\end{abstract}

\section{INTRODUCTION}

Reptile species are declining in numbers and range throughout the UK, which has prompted research to understand the reasons for these trends (Beebee \& Griffiths, 2000). Conclusions from this research have resulted in recommendations for conservation, includinglegal protection of animals and habitat, and the implementation of habitat management practices to benefit these animals (Edgar et al., 2010; Gleed-Owen \& Langham, 2012).

Scotland has in some areas healthy populations of reptiles, including the adder (McInerny \& Minting, 2016). One area in Scotland where adders have been studied is Loch Lomond, $40 \mathrm{~km}$ north of Glasgow, which has revealed much information about their biology, distribution and habitat preferences (McInerny, 2014a, 2014b, 2016a, 2016b, 2017).

Here we summarise two projects which addressed the conservation of adders at Loch Lomond. One involved the creation of an environmental mitigation plan to ameliorate the effects of the installation of a hydroelectric scheme (McInerny, 2016a), and the other the study of a population on a golf course in highly managed habitat (McInerny, 2016b). In both cases monitoring of the populations revealed stable numbers of adders, suggesting that these reptiles can, when appropriate consideration and action are put in place, co-exist with humans.

\section{HYDROELECTRIC SCHEME ENVIRONMENTAL MITIGATION PLAN}

Study site and survey work

The study site is a replanted mixed native forest on south and west facing hill slopes flanking the east shore of Loch Lomond (McInerny, 2014a, 2017). This contains areas of bracken (Pteridium spp.), bramble (Rubus fruticosus agg.), gorse (Ulex spp.) and heather (Calluna vulgaris), amongst scattered small trees and bushes of various species.

Artificial cover objects, made from $50 \mathrm{~cm} \times 50 \mathrm{~cm}$ roofing felt, were distributed in March 2012 (McInerny, 2017). These, and areas around the felts, were examined visually about once a week for reptiles from early February until November. The site was monitored from 2012 to 2015, with 36-58 visits each year. The location, number, maturity and gender of reptiles were recorded on each visit; these were recorded as day counts, and are plotted graphically in Fig. 1. Underground reptile hibernation sites were also mapped. Highest reptile densities were found in an area approximately 0.6 hectares in size at the lower parts of the study site.

\section{Environmental mitigation plan}

A hydroelectric scheme was proposed for construction in 2014 which involved the diversion of water through a $2 \mathrm{~km}$ underground pipe from a burn $300 \mathrm{~m}$ down a hillside to a turbine powerhouse, before re-entering the burn (McInerny, 2016a). The proposed site of the turbine powerhouse coincided with the area that contained the highest reptile densities revealed by the 2012 survey work.

As a prelude to the environmental mitigation plan, the entire length of the proposed pipeline and turbine house was surveyed for reptiles. Three visits were made during March and early April 2013, the optimum time of the year to locate these animals in Scotland, when vegetation has not grown, and the reptiles bask for long periods in the cool air and weak early spring sun. The surveys confirmed the distribution of adders revealed by the 2012 survey and formed the basis of the mitigation plan, which had three parts: 

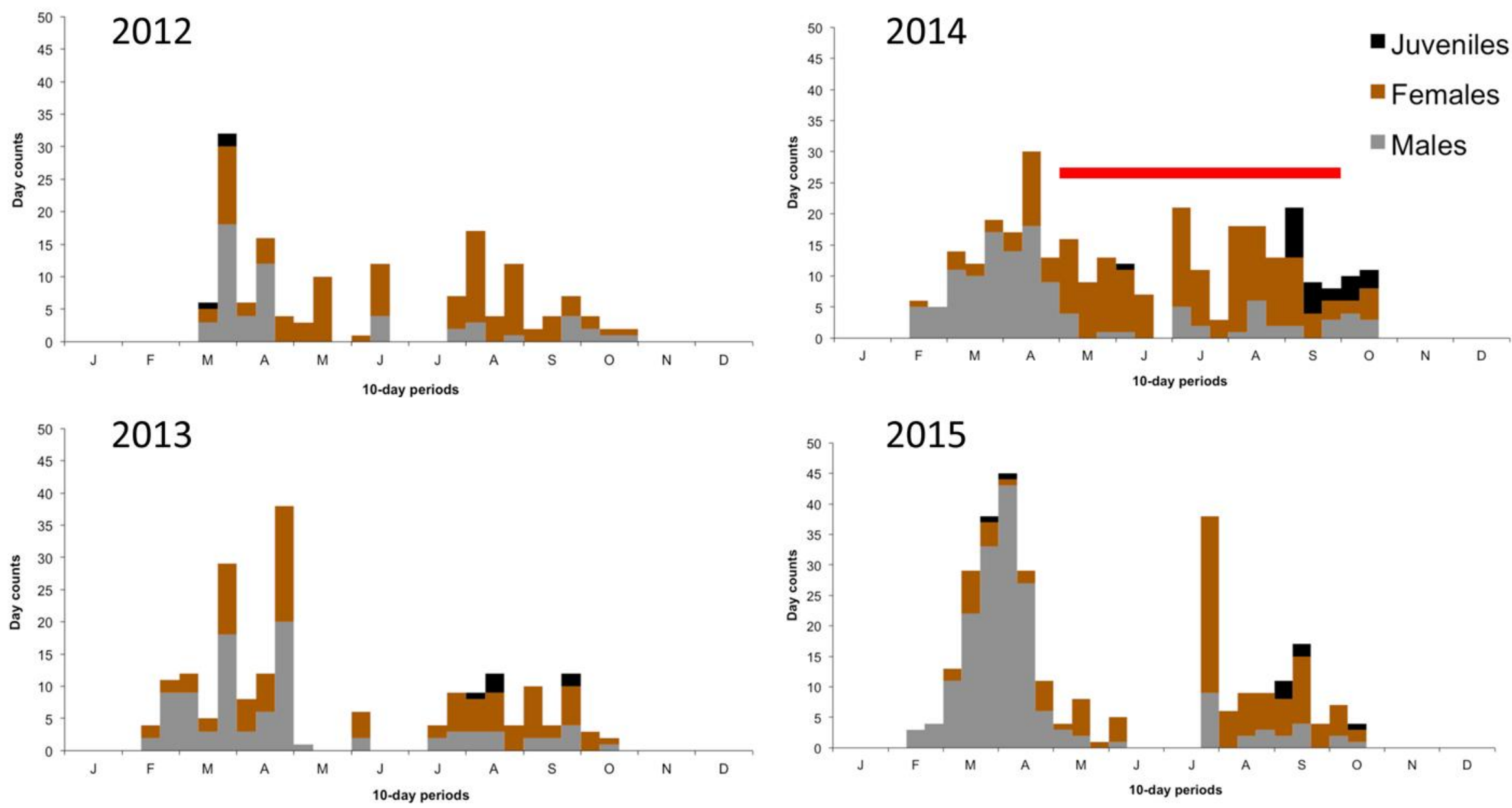

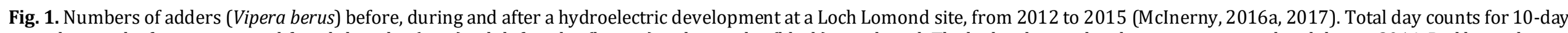

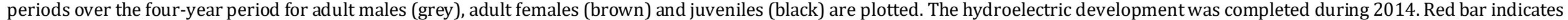
the construction period from May to September, with the reptile-proof fencing present from January to November. 
1) A revision of the route of the underground water pipe to avoid reptile hibernation sites.

2) The erection of a reptile-proof fence around the development corridor at the lower part of the site where highest reptile densities were found. The fence was $\sim 50 \mathrm{~cm}$ high plastic with $\sim 10 \mathrm{~cm}$ below the ground surface (Fig. 2A,B). The fencing was installed during January 2014 to minimise impact on mapped reptile hibernation sites, when reptiles were hibernating underground.

3) The removal of all reptiles within the developmental corridor to outside the fence, and the maintenance of the fence and the adjacent habitat during construction.

The hydroelectric development lasted from May to September 2014, with the fence removed during November 2014 when reptiles had returned to underground hibernation sites (Fig. 2C).

\section{Results and conclusions}

Surveys of adders from 2012 to 2015 in areas adjacent to the development corridor revealed over 200 individuals at the site, with 60-80 different snakes observed each year (Fig. 1; McInerny, 2016a). Importantly, similar numbers of animals were counted each year. Numbers did not decline over the survey period, and instead were stable, indicating that the hydroelectric development had not affected the population, at least in the short term. Furthermore, adders were observed mating and carrying developing young close to the development, showing that they were not disturbed by the noise and activity of the construction site.

\section{GOLF COURSE POPULATIONS \\ Study site and survey work}

The study site is an 18-hole golf course in the vicinity of Loch Lomond, about 50 hectares in size on a south facing slope, with managed areas of cut grass on tees, fairways and greens, interspersed with areas of bracken, gorse and brambles (Fig. 3; McInerny, 2016b).

Artificial cover objects were not used due to public access at the site and the possibility of interfering with rounds of golf, with reptiles identified by visual surveys about once a week from early February until November. The site was monitored from 2012 to 2016, with 10-20 visits each year. The location, number, maturity and gender of reptiles were recorded on each visit; these were recorded as day counts and are shown in Table 1, and plotted graphically in Fig. 4. Underground reptile hibernation sites were also mapped.

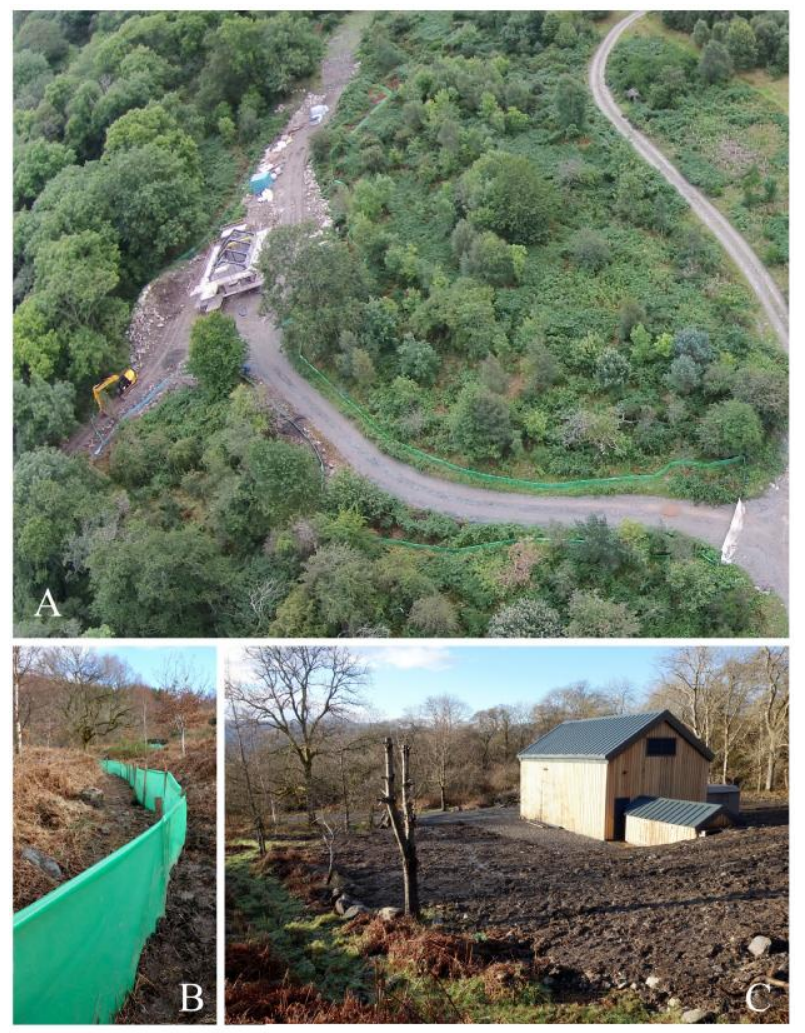

Fig. 2. Loch Lomond hydroelectric development at a site containing high densities of adders (Vipera berus) and other reptiles (McInerny, 2016a). (A) Arial view of the lower section of the construction site, August 2014. This shows the fenced area encompassing the construction site containing the partially built turbine powerhouse, the cleared areas where the underground water pipes had been laid, a movable heavy sheet "gate" placed across the access road, and the intact habitat surrounding the site. (B) Reptile-proof fencing that surrounded the construction site, February 2014; this was $\sim 50 \mathrm{~cm}$ high with $\sim 10 \mathrm{~cm}$ below the ground. (C) The completed turbine powerhouse, with fencing removed, November 2014. (Photos: C. McInerny) 


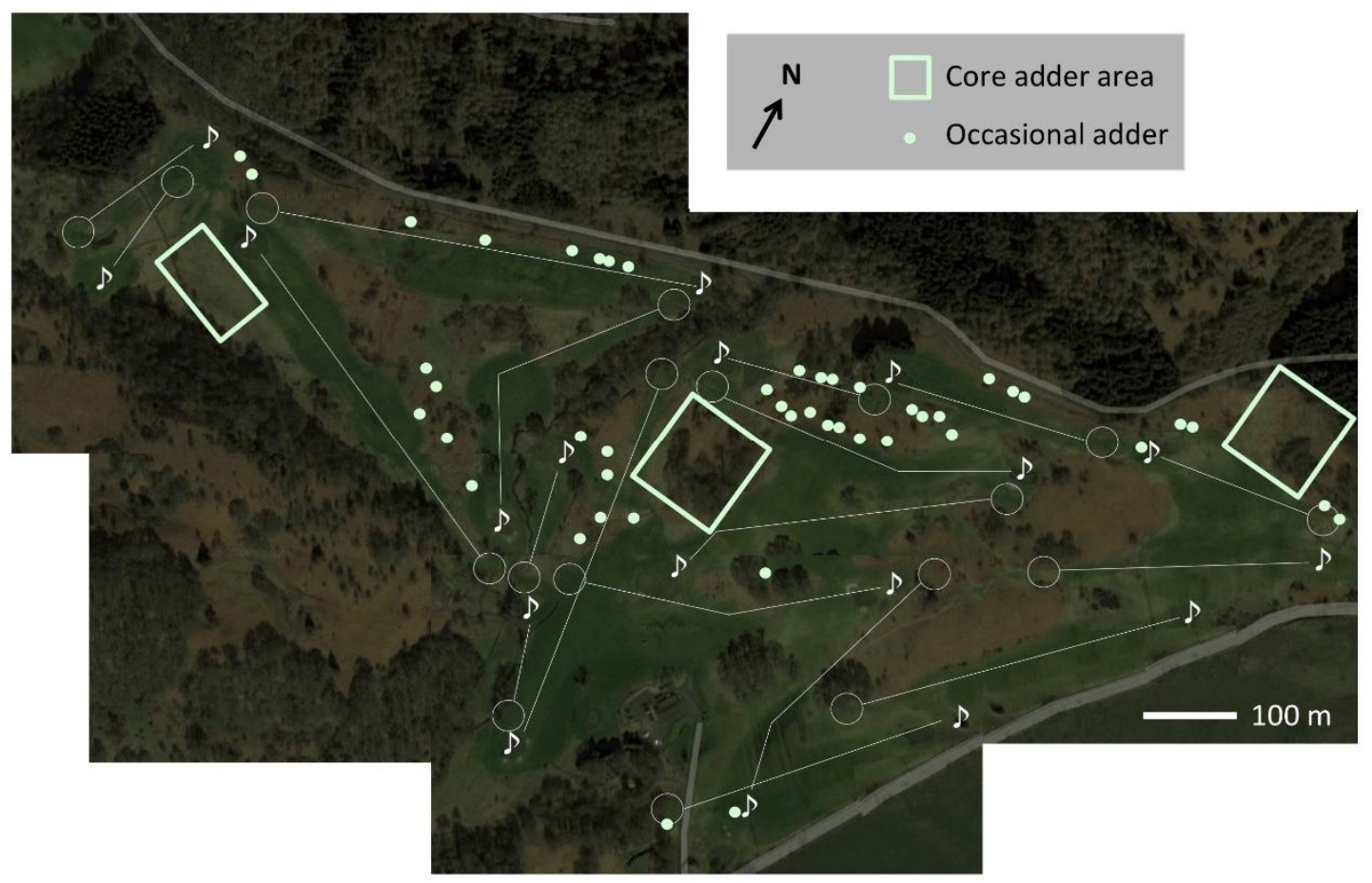

Fig. 3. Distribution of adders (Vipera berus) on a Scottish golf course, 2012 to 2016 (McInerny, 2016b). Core areas where snakes hibernated and were seen regularly are indicated by boxes; locations of occasional sightings are shown by dots. The layout of the golf course is mapped, with the 18 holes marked: open circles, tees; lines, fairways; $\delta$, greens and holes.

\begin{tabular}{|c|c|c|c|c|c|c|}
\hline & \multirow[t]{2}{*}{ Visits } & \multirow{2}{*}{$\begin{array}{l}\text { Day Counts } \\
\text { Total }\end{array}$} & \multicolumn{4}{|c|}{ Individuals } \\
\hline & & & Total & Male & Females & Juvenile \\
\hline 2012 & 20 & 36 & 19 & 6 & 11 & 2 \\
\hline 2013 & 17 & 37 & 26 & 14 & 10 & 2 \\
\hline 2014 & 16 & 77 & 39 & 13 & 22 & 4 \\
\hline 2015 & 10 & 21 & 10 & 6 & 4 & - \\
\hline 2016 & 14 & 36 & 23 & 13 & 10 & - \\
\hline
\end{tabular}

Table 1. Numbers of adders (Vipera berus) on a Scottish golf course, 2012 to 2016 (McInerny, 2016b). For each year, the number of visits, total of day counts, and the minimum numbers of individual adult males, adult females and juveniles are shown. Individuals were identified through their head-scale patterns. During the five-year period a minimum of 54 different snakes were recognised.

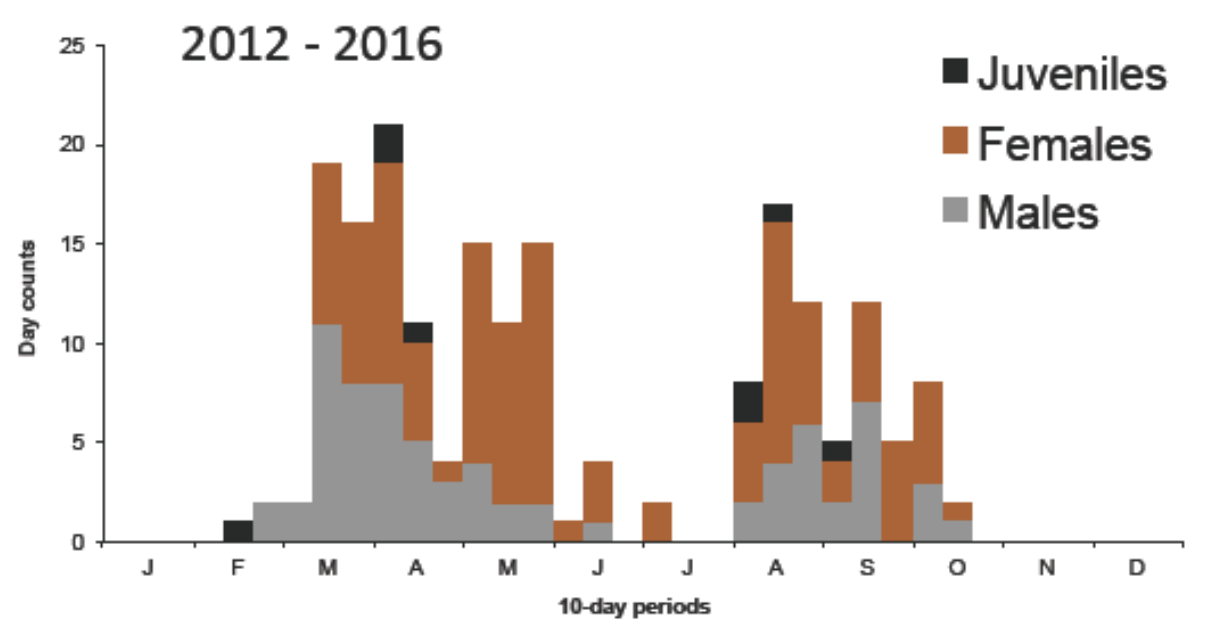

Fig. 4. Total numbers of adders (Vipera berus) on a Scottish golf course, 2012 to 2016 (McInerny, 2016b). Total day counts for 10-day periods over the five-year period for adult males (grey), adult females (brown) and juveniles (black) are plotted. 


\section{Results and conclusions}

Surveys of adders from 2012 to 2016 revealed over 54 individual at the site, with 10-39 different snakes observed each year (Table 1; Fig. 4; McInerny, 2016b). Animals were noted throughout the golf course, though with concentrations in some areas where snakes were seen more regularly, usually near to hibernation sites (Fig. 3). Numbers were constant each year of the survey period, with young observed, suggesting that the life cycles of the adders were unaffected by the management practices of the golf course and that the population was being maintained at the site.

\section{DISCUSSION \\ Reptiles in managed habitats}

This paper describes two different projects, which considered populations of adders in habitats that have been influenced or modified by humans. In both cases the adder numbers were not affected and the populations persisted. These studies suggest that where appropriate actions are put in place or where habitat management is sympathetic, adders and humans can co-exist. In a world increasingly changed by mankind, these studies offer examples where humans and reptiles can live together, to the benefit of both.

\section{Reptile habitats in Scotland}

The studies described here identified habitats in Scotland which supported high densities of adders and other reptiles, including common lizards (Zootoca vivipara) and slow-worms (Anguis fragilis). These were open areas of bracken, gorse and brambles on south and west facing slopes, with small trees and bushes, often with burns and wet areas nearby. Many areas containing this habitat are present in the Loch Lomond National Park where the author has discovered a number of populations of adders, common lizards and slow-worms (McInerny, 2014b). Indeed, adders and other reptiles are found throughout mainland Scotland and some west coast islands (McInerny \& Minting, 2016), often present in comparable habitat, which is widespread and familiar. In this context such habitat should be valued as a refuge for reptiles, and so protected and preserved.

\section{ACKNOWLEDGEMENTS}

I thank the landowners, wardens, the Club Secretary, golfers and groundsmen for permission and understanding to monitor reptiles at the two study sites. The survey work in 2014-2015 was supported by travel grants awarded by the Glasgow Natural History Society from the Professor Blodwen Lloyd Binns bequest, and Clyde Ecology.

\section{REFERENCES}

Beebee, T.J.C. \& Griffiths, R.A. (2000). Amphibians and Reptiles. Harper Collins, London.

Edgar, P., Foster, J. \& Baker, J. (2010). Reptile Habitat Management Handbook. Amphibian and Reptile
Conservation, Bournemouth.

www.arc-trust.org/habitat-management-handbooks

Gleed-Owen, C. \& Langham S. (2012). The Adder Status Project - a Conservation Condition Assessment of the Adder (Vipera berus) in England, with Recommendations for Future Monitoring and Conservation Policy. CGO Ecology Limited Report.

McInerny, C.J. (2014a). Observations on a population of adders, slow-worms and common lizards on Loch Lomondside, Scotland. The Glasgow Naturalist 26(1), 63-68.

McInerny, C.J. (2014b). Habitat preferences of European adders at Loch Lomond, Scotland. The Glasgow Naturalist 26(1), 69-74.

McInerny, C.J. (2016a). Reptile populations persist following the installation of a hydroelectric scheme at Loch Lomond, Scotland. The Herpetological Bulletin 135, 11-14.

McInerny, C.J. (2016b). Co-existence of reptiles and humans: observations on a population of northern vipers on a Scottish golf course. The Herpetological Bulletin 138, 6-9

McInerny, C.J. (2017). Observations on co-existing populations of adders, slow-worms and common lizards at Loch Lomond, Scotland: implications for conservation. The Glasgow Naturalist 26(3), 32-41.

McInerny, C.J. \& Minting, P. (2016). The Amphibians and Reptiles of Scotland. The Glasgow Natural History Society, Glasgow. Free download at www.glasgownaturalhistory.org.uk/books.html

Sewell, D., Griffiths, R.A., Beebee, T.J.C., Foster, J. \& Wilkinson, J.W. (2013). Survey Protocols for the British Herpetofauna. Amphibian and Reptile Conservation, Bournemouth. 